\title{
XIV. On the dissociation degree of some electrolytes at $0^{\circ}$
}

\section{R. W. Wood}

To cite this article: R. W. Wood (1896) XIV. On the dissociation degree of some electrolytes at $0^{\circ}$, Philosophical Magazine Series 5, 41:249, 117-120, DOI: 10.1080/14786449608620821

To link to this article: http://dx.doi.org/10.1080/14786449608620821

曲 Published online: 08 May 2009.

Submit your article to this journal $\pi$

Џll Article views: 3

Q View related articles $\longleftarrow$ 
magnetizing coil about the sample for that current, and by direct proportion betweon horizontal displacement in calibration, and the horizontal displacement of any point on the curve, we obtain in Absolute Units the magnetic force corresponding to any point on the curve. Having thus calibrated the curves of either continuous or alternating current magnetic cycles in Absolute Units, the energy losses, $\int I d \mathrm{H}$, may be obtained by taking the area of the curves in the usual way.

Although this description has only been concerned with the curve-tracer as a means of measuring the magnetie quality of, and the energy losses in iron and other metals, when carried through magnetic cycles, it plainly lends itself to such operations as direct tracing of alternating-current and electromotive-force curves, the investigation of the nature and amount of iron losses in alternating-current transformers, the measurement of the power in any electrical circuit; \&c.

XIV. On the Dissociation Degree of some Electrolytes at $0^{\circ}$. By R.W. Wood*.

TYHE values obtained by the lowering of the freezing-point 1 for the dissociation-degree of dissolved electrolytes are always a little smaller than those calculated from the electrical conductivity.

Meyer Wildermann $\dagger$ has recently lessened the difference by the use of a more accurate method for the freezing-point determinations, and has expressed the opinion that the cause of the discrepancies lay in the fact that the electrical conductivities have been determined at a higher temperature $\left(18^{\circ}-25^{\circ}\right)$.

At Prof. Jahn's suggestion, I have determined the conductivity of certain Salts and Acids in solutions of varying concentration at $0^{\circ}$, for the purpose of reckoning the Dissociation-degree at this temperature, and the results indicate that, in dilute solutions, the dissociation-degree is practically independent of the temperature.

The determinations were made according to the Kohlrausch method, and the conductivity of the distilled water used in the experiments was determined at different temperatures and taken into account.

The value expressing the conductivity of. infinitely dilute

* Translated from the Zeitschrift für phys. Chemie, xviii. p. 3 (1895). Communicated by the Author.

$\dagger$ Phil. Mag. July 1895. 
solutions was calculated by means of the temperature-coefficient from the values found by Kohlrausch and Ostwald for $18^{\circ}$ and $25^{\circ}$.

In the case of the acids, it was determined by the aid of the Kohlrausch law.

The results of the determinations made with potassium and sodium chloride are as follows :-

\begin{tabular}{|c|c|c|c|c|c|}
\hline \multicolumn{3}{|c|}{ Potassium Chloride $0^{\circ}$. } & \multicolumn{3}{|c|}{ Sodium Chloride $0^{\circ}$. } \\
\hline$\nabla$. & $\lambda$. & $\frac{\lambda_{v}}{\lambda_{\infty}}$. & v. & $\lambda$. & $\frac{\lambda_{v}}{\lambda_{\infty}}$ \\
\hline $\begin{array}{r}1 \\
2 \\
4 \\
8 \\
16 \\
32 \\
64 \\
128 \\
256 \\
512 \\
1024 \\
\infty\end{array}$ & $\begin{array}{l}61 \cdot 10 \\
62 \cdot 49 \\
64 \cdot 46 \\
66 \cdot 47 \\
68 \cdot 70 \\
70.66 \\
72 \cdot 60 \\
73 \cdot 90 \\
75 \cdot 30 \\
75 \cdot 90 \\
76 \cdot 35 \\
77 \cdot 80\end{array}$ & $\begin{array}{r}78 \cdot 53 \\
80 \cdot 30 \\
82 \cdot 78 \\
85 \cdot 44 \\
88 \cdot 30 \\
90 \cdot 82 \\
93 \cdot 32 \\
94 \cdot 99 \\
96 \cdot 79 \\
97 \cdot 56 \\
98 \cdot 14 \\
100 \cdot 00\end{array}$ & $\begin{array}{r}1 \\
2 \\
4 \\
8 \\
16 \\
32 \\
64 \\
128 \\
256 \\
512 \\
1024 \\
\infty\end{array}$ & $\begin{array}{l}44 \cdot 59 \\
48 \cdot 00 \\
50 \cdot 76 \\
53 \cdot 31 \\
55 \cdot 36 \\
57 \cdot 20 \\
59 \cdot 13 \\
60 \cdot 10 \\
61 \cdot 13 \\
62 \cdot 43 \\
63 \cdot 70 \\
65 \cdot 00\end{array}$ & $\begin{array}{r}68 \cdot 60 \\
73 \cdot 85 \\
78.09 \\
82 \cdot 02 \\
85 \cdot 17 \\
88 \cdot 00 \\
90 \cdot 77 \\
92 \cdot 46 \\
94 \cdot 06 \\
96 \cdot 05 \\
98.00 \\
100 \cdot 00\end{array}$ \\
\hline
\end{tabular}

$\mathrm{V}$ signifies the volume containing a gram-molecular weight of the salt, $\lambda$ the conductivity, and $\frac{\lambda_{v}}{\lambda_{\infty}}$ the dissociation-degree.

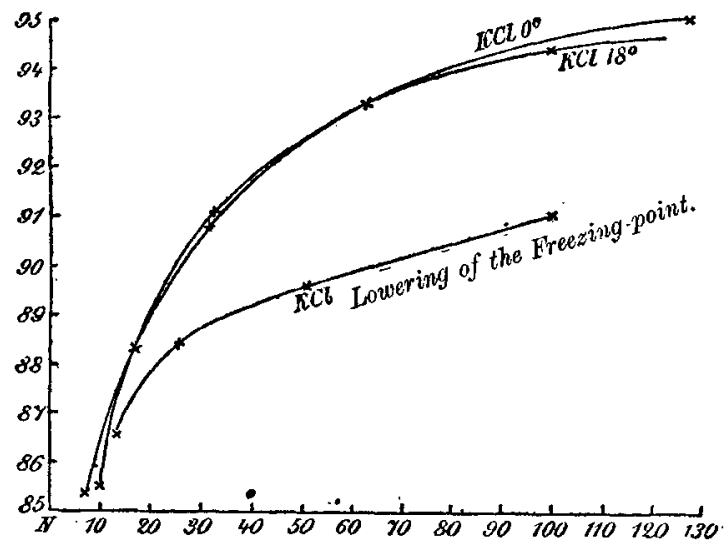

If we take as ordinates the values obtained by Kohlrausch for the dissociation-degree at $18^{\circ}$, and those which I have 
found for $0^{\circ}$, and as abscissæ the values of $\mathrm{V}$, we find that the curves are almost coincident, while the one representing the values obtained by Wildermann from the lowering of the freezing-point runs considerably lower, as the diagram indicates.

The values of $\lambda_{\infty}$ for $0^{\circ}$ in the following table is calculated by means of the temperature-coefficient of the most dilute of the investigated solutions from the values of $\lambda_{\infty}$ given by Ostwald for $25^{\circ}$.

For di- and trichloracetic acids the following values were found :-

\begin{tabular}{|c|c|c|c|c|c|c|}
\hline \multicolumn{7}{|c|}{ Dichloracetic Acid, $\frac{1}{\lambda} \frac{d \lambda}{d I^{\prime}}=0.0148$. } \\
\hline \multirow{2}{*}{ V. } & \multirow{2}{*}{$\begin{array}{c}\lambda \\
\text { for } 0^{\circ}\end{array}$} & \multirow{2}{*}{$\frac{\lambda_{n}}{\bar{\lambda}_{\infty}}$} & \multicolumn{2}{|c|}{$\lambda$ for $25^{\circ}$} & \multirow{2}{*}{$\begin{array}{l}\frac{\lambda_{v}}{\lambda_{\infty}} \\
\text { for } 25^{\circ}\end{array}$} & \multirow{2}{*}{$\begin{array}{c}\text { Dissociation- } \\
\text { degree by } \\
\text { lowering of } \\
\text { freezing- } \\
\text { point. }\end{array}$} \\
\hline & & & Wood. & Ostwald. & & \\
\hline $\begin{array}{c}32 \\
64 \\
128 \\
256 \\
512 \\
\infty\end{array}$ & $\begin{array}{l}174 \\
194 \cdot 2 \\
207 \cdot 9 \\
216 \cdot 1 \\
221 \cdot 9 \\
227 \cdot 0\end{array}$ & $\begin{array}{r}76 \cdot 6 \\
855 \\
91.5 \\
952 \\
97.7 \\
3000\end{array}$ & $\begin{array}{c}2523 \\
\overline{317} \cdot 4 \\
\overline{351 \cdot 8} \\
-\end{array}$ & $\begin{array}{l}2531 \\
2907 \\
3175 \\
337 \cdot 0 \\
352 \cdot 2 \\
361 \cdot 0\end{array}$ & $\begin{array}{r}70 \cdot 2 \\
80.5 \\
88 \cdot 0 \\
93 \cdot 4 \\
97 \cdot 6 \\
1000\end{array}$ & $\begin{array}{l}740 \\
84.0\end{array}$ \\
\hline \multicolumn{7}{|c|}{ Trichloracetic Acid, $\frac{1}{\lambda} \frac{d \lambda}{d \mathrm{~T}}=0 \cdot 0149$. } \\
\hline $\begin{array}{c}32 \\
61 \\
128 \\
256 \\
512 \\
\infty\end{array}$ & $\begin{array}{l}206 \cdot 0 \\
211 \cdot 9 \\
216 \cdot 6 \\
219 \cdot 7 \\
221 \cdot 9 \\
2 \geq 4 \cdot 7\end{array}$ & $\begin{array}{r}91 \cdot 7 \\
94 \cdot 3 \\
96 \cdot 4 \\
97 \cdot 7 \\
93 \cdot 7 \\
100 \cdot 0\end{array}$ & $\begin{array}{c}324 \cdot 0 \\
333 \cdot 5 \\
341 \cdot 5 \\
348 \cdot 1 \\
3530 \\
-\end{array}$ & $\begin{array}{l}323 \cdot 0 \\
332 \cdot 8 \\
341 \cdot 0 \\
348 \cdot 0 \\
353 \cdot 7 \\
358 \cdot 0\end{array}$ & $\begin{array}{r}90 \cdot 1 \\
93 \cdot 0 \\
95 \cdot 3 \\
97 \cdot 0 \\
98 \cdot 8 \\
100 \cdot 0\end{array}$ & $\begin{array}{l}88 \cdot 1 \\
94 \cdot 0\end{array}$ \\
\hline
\end{tabular}

For control, the conductivity of the two acids at infinite dilution at $0^{\circ}$ was calculated from the values obtained for $5 \frac{1}{12}$ normal solutions of their potassium salts, potassium chloride, and hydrochloric acid, according to the Kohlrausch law. The following are the values found, which agree very well with those in the table:-

$$
\begin{array}{ll}
\text { Dichloracetic acid } & \cdot \lambda_{\infty}=228 . \\
\text { Trichloracetic acid } & \cdot \lambda_{\infty}=225 \cdot 2
\end{array}
$$

The dissociation-degree of the two acids is apparently 
independent of the temperature, and Wildermann's supposition has not been confirmed. The deviations of the values for the dissociation-degree calculated by the two methods still remain.

In all probability the cause lies in the inexact determination of the freezing-point of dilute solutions. We know from the investigations of Nernst and Abegg* that its exact determination is attended with great difficulty.

\section{The Duration of the Flash of Faploding Oxyhydrogen.} By R. W. Wood t.

SOME time ago, in endeavouring to photograph the ex$\$$ plosion-wave, if it may be so termed, of electrolytic gas by means of the electric spark, I was struck with the fact that the duration of the flash was exceedingly small. In many cases I found that the glass bulbs, which were thinner than paper, were photographed by the light of the incandescent gas within before the walls had given way. The striations on the glass were sharp and the outlines of the bulb were perfectly distinct, the interior being quite filled with a bright glow.

I have recently repented and enlarged somewhat on these experiments with a view to determine the duration of the Hlash.

The bulbs were blown very thin, with a quill-like neck at each end. They were filled with a mixture of oxygen and hydrogen by means of an electrolytic apparatus, and two copper wires were then sealed in with wax, with a gap of perhaps half a millimetre between them.

A pendulum, made by hanging a heavy lend ball on a fine wire, was hung in front of the bulb, the copper wires of which were counected with the terminals of a small inductorium.

From the bottom of the ball projected a pin which came in contact with a slip of platinum foil mounted edgewise before the bulb, and the pendulum and foil were put in circuit with the primary coil of the inductorium. This arrangement insured the explosion of the bulb at the moment when the pendulum passed its point of equilibrium, and by calculating the velocity of the pin's head and measuring the amount of blur of the photographic image the duration of the flash could be approximately determined. The camera, provided with a Zeiss lens of large aperture, was placed near enongh

* Zeirschr. fiir phys. Chemir, xv. p. 681 (1894).

$\uparrow$ Communicated by the Author. 